\title{
Using EDX/SEM to Study Heavy Metal Uptake and Elemental Composition in Plant Tissues
}

\author{
Yadong Qi*, Kun Lian**, Kit L. Chin*, and Robert L. Ford* \\ *Southern University and A\&M College, Baton Rouge LA 70813 \\ **Center for Advanced Microstructures and Devices, Louisiana State University, Baton Rouge LA \\ 70803
}

Analytical instruments used commonly to study elemental concentrations of plant tissues include inductively coupled plasma-mass spectrometry system, atomic absorption spectrometry, and other procedures designated for specific elements. These instruments serve as good tools to analyze a specified chemical element or provide partial multi-element analysis. However, sample preparation and analytic procedures for these instruments are time consuming and costly. A preliminary study using an energy dispersive X-ray (EDX) spectroscopy at the Center for Advanced Microstructures and Devices, Louisiana State University-Baton Rouge clearly demonstrated the feasibility of this technology for instantaneous analyses of elemental composition profiles of plants and the potential for monitoring heavy metal pollutants based on uptake by plants. The EDX technology requires minimum sample preparation time and sample size.

Leaves and trunk were sampled from $10 \mathrm{~cm}$ diameter black willow (Salix nigra Marsh) trees growing at the bank of Mississippi river near the campus of Southern University-Baton Rouge, Louisiana in May. The trunk samples were obtained using an increment borer at $1.3 \mathrm{~m}$ above ground. Plant samples were vacuum air-dried and analyzed qualitatively and quantitatively using an EDX Phoenix Microanalyzer, which is equipped with a Hitachi Scanning Electron Microscopy (SEM). The microanalyzer has qualitative, quantitative, imaging, and element mapping capabilities. This EDX system can detect light elements with $0.1 \%$ detectability limit and heavy elements with better than $0.1 \%$ detectability limit. The software used for analysis is SEM QUANT version 3.0.from EDAX Inc. The EDX scan time was set for 200 seconds, scan surface covered an area of 300um x 250um, and scan depth was about $20 \mathrm{um}$.

FIG. 1 illustrated the EDX spectra of the sapwood region of a trunk core and the adaxial surface of a leaf of black willow. In the trunk spectra twelve elements essential to plant growth were detected by the EDX included $\mathrm{C}, \mathrm{O}, \mathrm{N}, \mathrm{K}, \mathrm{P}, \mathrm{S}, \mathrm{Mg}, \mathrm{Ca}, \mathrm{Cl}, \mathrm{Mn}, \mathrm{Fe}$ and $\mathrm{Co}$; and other nonessential elements such as $\mathrm{Pb}, \mathrm{Si}, \mathrm{Al}$, and $\mathrm{Na}$ were also discovered in the wood (FIG. 1a). In contrast, leaf spectra revealed ten essential and three nonessential elements and no heavy metal; and leaves also contained a higher level of $\mathrm{K}$ than the trunk (FIG. 1b). In trees, about $96 \%$ of the dry weight of plants is accounted by atoms of $\mathrm{H}, \mathrm{O}, \mathrm{C}$, and $\mathrm{N}$, the major chemical constitutes of biomass. The remaining $4 \%$ is divided unequally among the other 12 essential nutrients and numerous nonessential elements [1]. The quantitative analysis of the elemental composition by weight based on an average of five consecutive EDX scans from the sapwood to pith of a $5 \mathrm{~cm}$ trunk core in black willow is presented in FIG.2, which indicated approximately $95 \%$ of the wood dry weight was accounted for by atoms of $\mathrm{C}, \mathrm{O}$, and $\mathrm{N}$, and $5 \%$ was accounted for the rest of the elements. $\mathrm{H}$ was not shown because it is too light to be detected by the EDX. The presence of $\mathrm{Pb}$ in tree trunk indicated the heavy metal uptake and accumulation via roots of the trees growing at the bank of Mississippi River, which could have been polluted with lead. In conclusion, EDX/SEM technology offers a new approach to 
instantaneous analyses of elemental composition of various plant tissues and organs. This technology could have broad applications in the field of biological sciences, such as determination of heavy metal uptake and accumulation by plants, and detection of heavy metal pollution in the environment.

\section{References}

[1] J.P. Kimmins, Forest Ecology, $2^{\text {nd }}$ edition, Prentice Hall, 1997.

[2] This research project was supported by an SUBR Environmental Technology Consortium Research and Development Grant under Federal Award Number DE-FC04-90-AL-66158.
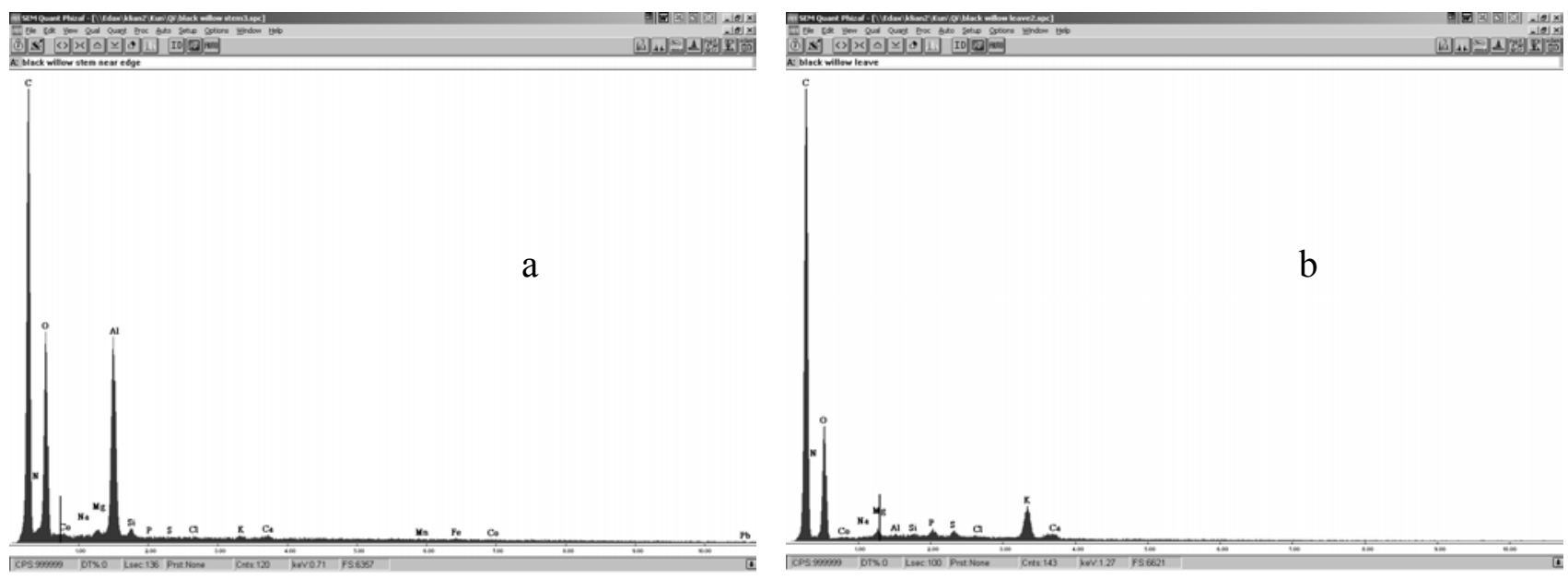

FIG. 1. The energy-dispersive X-ray spectra of the sapwood region of a trunk core (a) and the adaxial surface of a leaf (a) in black willow.

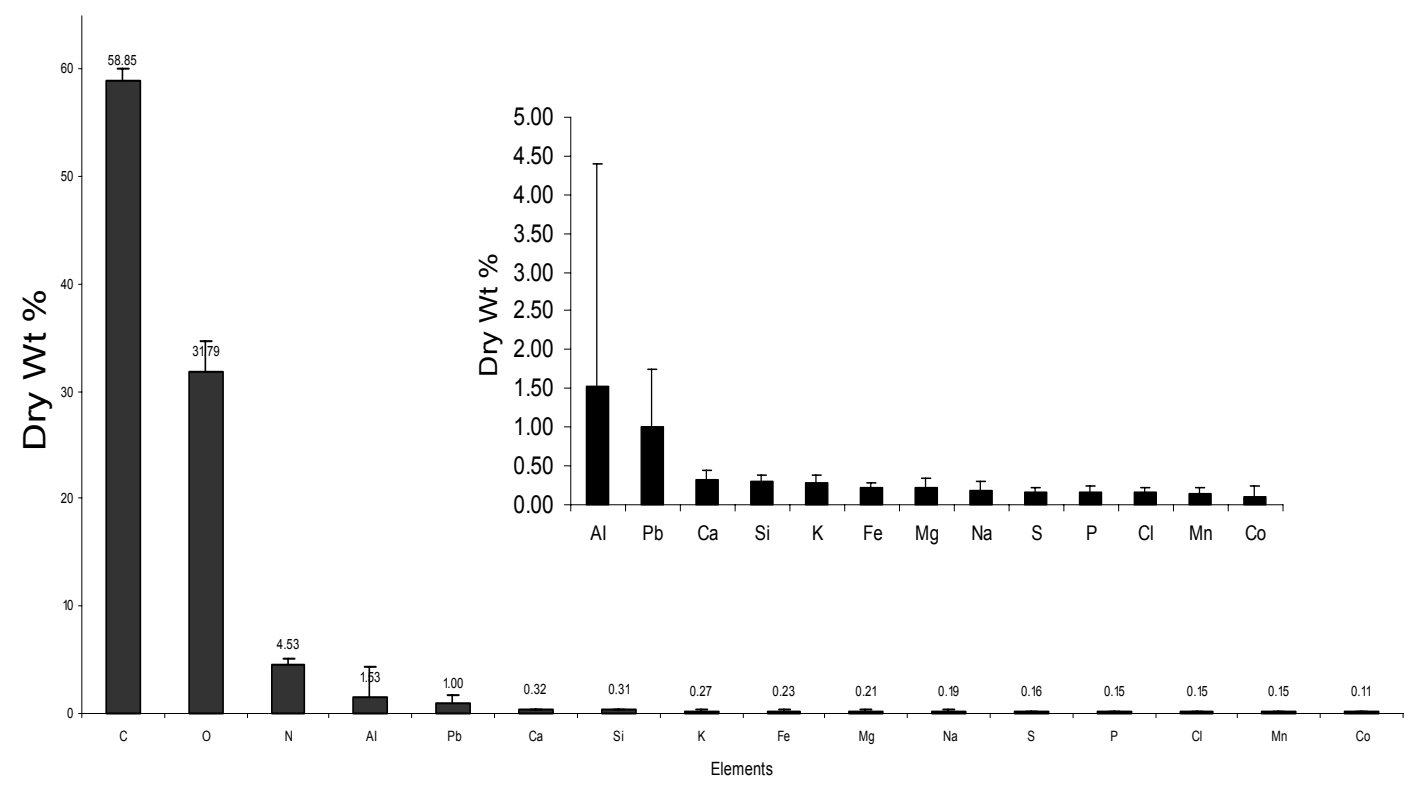

FIG. 2. Quantitative analysis of the elemental composition by weight based on an average of five consecutive EDX scans from the sapwood to pith of a $5 \mathrm{~cm}$ trunk core in black willow. 